\title{
ПРОБЛЕМЫ РЕАЛИЗАЦИИ ПРИНЦИПОВ ДОБРОСОВЕСТНОСТИ И СПРАВЕДЛИВОСТИ ПРИ ФОРМИРОВАНИИ РЕЕСТРА ТРЕБОВАНИЙ КРЕДИТОРОВ В РОССИЙСКОЙ ФЕДЕРАЦИИ
}

\section{THE PROBLEMS OF IMPLEMENTING THE PRINCIPLES OF GOOD FAITH AND JUSTICE IN THE CREATION OF THE LIST OF CREDITORS IN THE RUSSIAN FEDERATION \\ L. Danilyuk}

Summary. The article is devoted to the study of the enforcement of the principles of good faith and justice in bankruptcy. The article analyzes the legal mechanics of the exercise of these principles in creation of the list of creditors. The author analyzes the legislation, as well as materials of judicial practice, and indicates the shortcomings of legal regulation.

Keywords: bankruptcy, list of creditors, good faith, principle of justice.
И нститут несостоятельности (банкротства) является неотъемлемой частью рыночной экономики, поскольку позволяет выводить неплатежеспособных должников из гражданского оборота. Большое значение в регулировании института банкротства имеют принципы права, то есть основные положения, идеи, которые положены в основу правовой регламентации соответствующих общественных отношений $[1$, С. 98,38 , C. 38].

Российское конкурсное законодательство не содержит легального перечня принципов, однако такие принципы выводятся доктриной $[6,17,19]$. Исследуют проблематику принципов конкурсного права и иностранные ученые [39].

Отметим, что институт банкротства опирается на общеправовые принципы, а также на принципы гражданского права, которые, в свою очередь, могут являться внутриотраслевыми, или же общеправовыми, но получившими специфический окрас гражданского права. Большое значение как для гражданского права, так и для регламентации несостоятельности (банкротства) имеют принципы добросовестности и справедливости.

Исторически принцип справедливости развивался в древних цивилизациях исключительно в рамках фи-
Данилюк Лариса Александровна

Преподаватель, Финансовый Университет при Правительстве Российской Федерации; адвокат, член коллегии адвокатов «ЭксЛедж» г. Москвы Moscow.advocate@mail.ru

Аннотация. Статья посвящена изучению реализации принципов добросовестности и справедливости в банкротстве. В статье анализируются правовые механизмы, способствующие реализации данных принципов при формировании реестра требований кредиторов. Автор анализирует законодательство, а также материалы судебной практики, и указывает на недостатки правового регулирования.

Ключевые слова: банкротство, реестр требований кредиторов, добросовестность, принцип справедливости.

лософско-этических учений. С правовой точки зрения справедливость начали рассматривать только в Древнем Риме [13, С. 17]. Основные начала справедливой жизни в понимании римского права могут быть выражены в формуле Ульпиана: «Жить честно, не делать никому вреда, каждому воздавать своё» $[16$, С. 70].

В современном российском правопорядке, имплементировавшем путем рецепции некоторые конструкции римского права, общеправовой принцип справедливости получил различное наполнение в каждой из отраслей права.

В гражданском законодательстве принцип справедливости не закреплён как самостоятельный принцип гражданского оборота; при этом он активно развивается в доктрине [8] и упоминается в отдельных статьях нормативных правовых актов. Из ст.ст. 2 и 6 ГК РФ [12] следует важный вывод: указанные в п.п. 1 и 2 ст. ГК РФ отношения регулируются гражданским законодательством или соглашением сторон; далее, если отсутствует соответствующая норма права или соглашение сторон, применяется обычай делового оборота; если отсутствует и такой обычай, применяется аналогия закона; если аналогия закона невозможна, применяется аналогия права, вместе с требованиями добросовестности, разумности и справедливости. В цивилистике справедли- 
вость определяется как готовность учитывать интересы других лиц и общественные интересы, нормы морали и нравственности (что выражается, в частности, в отказе от злоупотребления правами), соблюдать равенство в положении участников оборота [18]. Отметим интерес доктрины к исследованию данного вопроса $[2,7,9]$.

Принцип добросовестности, как и принцип справедливости, получил своё развитие еще в римском праве. Так, участникам гражданского оборота рекомендовалось строить свои взаимоотношения так, как принято среди честных, добропорядочных людей: ut inter bonos agier oportet. Суду же зачастую рекомендовалось рассматривать дела ex fide bona, что в отличие от судебного процесса stricti iuris предполагало большую свободу и самостоятельность судьи в анализе материала, возможность обращать внимание не на одну только букву закона и (или) договора, но главным образом и на его смысл, приспособляться к изменяющейся жизненной обстановке. В процессе bonae fidei судья получил право прибегать в качестве вспомогательного масштаба к bonum et aequum, к naturalis aequitas, к практике честных людей и т.п. Такое понимание принципа добросовестности воспринято и некоторыми современными правопорядками; оно может быть названо объективным.

Как справедливо отмечает А.В.Коновалов, добросовестность предполагает стремление участника гражданского оборота максимально исключить возможность нарушения его поведением субъективных прав и законных интересов других лиц, осуществлять свои права в строгом соответствии с их содержанием, объемом и назначением. Хотя добросовестность в контексте гражданско-правового принципа и имеет, подобно моральным нормам, этическую составляющую, все-таки в отличие от последних понятие добросовестности обладает вполне конкретным прагматичным содержанием, чрезвычайно важным для устойчивости гражданского оборота [18].

В субъективном же смысле добросовестность представляет собой осознание или, напротив, неведение фактов, с которыми закон связывает те или иные юридические последствия. Таким образом, в центре данного подхода находится заблуждение лица, которое может выражаться как в незнании действительных фактов, влияющих на правовые отношения, так и в ошибочной уверенности в их существовании. Такое заблуждение должно быть извинительным; также, не всякое сознание лица, что оно действует в согласии с правовым порядком, достаточно, чтобы признать это лицо добросовестным.

Таким образом, объединяя оба подхода, можно заключить, что добросовестность - это сочетание такого поведения субъекта, которое соответствует требовани- ям добропорядочности в отношениях всех субъектов оборота и не является эгоистичным, а также внутреннего осознания субъектом своей честности перед другими участниками.

Наиболее широкую и комплексную разработку принцип добросовестности, как отмечает доктрина, получил в немецком праве [20]. Нормы о добросовестности являются «открытыми», то есть позволяют судам уточнять, дополнять, развивать право исходя из потребностей общественных отношений [15]. Российское законодательство восприняло данный принцип относительно недавно: первого марта 2013 г. вступили в силу изменения Гражданского Кодекса РФ, среди которых - нормы о добросовестности, внесенные в п. 3, 4 ст. 1 и в ст. 10 ГК РФ. Данные нормы, будучи закрепленными в 1-м разделе ГК РФ, являются общим правилом для всех гражданских правоотношений. Согласно п. 3, 4 ст. 1 ГК РФ, при установлении, осуществлении и защите гражданских прав и при исполнении гражданских обязанностей участники гражданских правоотношений должны действовать добросовестно. Никто не вправе извлекать преимущество из своего незаконного или недобросовестного поведения.

Установив обязанность участников правоотношений действовать добросовестно, законодатель не определил критериев и пределов такого добросовестного поведения. Это, в принципе, объяснимо, поскольку в науке в ходе многовековой разработки этого понятия четкие критерии так и не были разработаны. Соответствующие разъяснения были даны Верховным Судом РФ в Постановлении Пленума от 23.06.2015 № 25 [25], который указал следующее: оценивая действия сторон как добросовестные или недобросовестные, следует исходить из поведения, ожидаемого от любого участника гражданского оборота, учитывающего права и законные интересы другой стороны, содействующего ей, в том числе в получении необходимой информации. Таким образом, в данном разъяснении представлен объективный подход к данной проблематике.

Упомянутое разъяснение, однако, также является очень общим и требует в каждом конкретном случае принятия решения судом по своему усмотрению. При таком подходе, безусловно, нельзя исключить ошибку в судейском усмотрении. Зачастую, участники гражданских правоотношений, хотя и понимают, что действуют недобросовестно, однако не могут с полной уверенностью осознавать, что их действия будут расценены судами как недобросовестные, что повлечет соответствующие негативные правовые последствия. И напротив, соблюдение всех общепринятых норм правомерного поведения субъектом гражданских правоотношений не гарантирует защиты от толкования судом его поведения как недобро- 
совестного. Модели определения добросовестного или недобросовестного поведения вырабатываются судебной практикой, поэтому, в частности, и в делах о банкротстве, особое значение приобретают правовые позиции судов.

Интересно в данном контексте доктринальное предложение выявлять злоупотребление правом посредством «сопоставления соответствующего действия с предполагаемыми (ожидаемыми) моделями поведения» [4].

Принцип добросовестности тесно связан с принципом недопустимости злоупотребления правом, поскольку, исходя из положений ГК РФ, злоупотребление правом - и есть недобросовестность. Ст. 10 ГК РФ устанавливает три основания применения принципа недопустимости злоупотребления правом: 1) осуществление гражданских прав исключительно с намерением причинить вред другому лицу (шикана), 2) действия в обход закона с противоправной целью, 3) иное заведомо недобросовестное осуществление гражданских прав (собственно злоупотребление правом). Таким образом, все три основания являются разновидностью злоупотребления правом, под которым в самом общем смысле понимается недобросовестное осуществление гражданских прав. Следует отметить, что ст. 10 ГК РФ не должна ограничивать толкование п. 4 ст. 1 ГК РФ, поскольку принцип добросовестности не ограничивается неодобрением лишь умышленных действий и не является наказанием, где должна учитываться вина [20, С. 33].

В п. 5 ст. 10 ГК РФ закреплена презумпция добросовестности, что означает обязанность одной стороны указать на недобросовестность другой стороны, при наличии оснований. Более того, как следует из вышеупомянутого Постановления Пленума Верховного Суда РФ от 23.06.2015 № 25, поведение одной из сторон может быть признано недобросовестным не только при наличии обоснованного заявления другой стороны, но и по инициативе суда, если усматривается очевидное отклонение действий участника гражданского оборота от добросовестного поведения. Это правило, с одной стороны, обеспечивает дополнительную защиту добросовестного участника, который в силу своей неопытности может не заметить недобросовестного поведения контрагента, а с другой - еще более расширяет компетенцию судов по определению недобросовестных участников оборота. Согласно ст. 10 ГК РФ, последствием недобросовестного поведения является отказ лицу в защите принадлежащего ему права полностью или частично со стороны суда, а также применение иных меры, предусмотренные законом.

В рамках процедуры несостоятельности (банкротства) принципы добросовестности и справедливости имеют большое значение и проявляются специфично. Значимость указанных принципов определяется необходимостью определения правильного соотношения интересов должника и кредиторов, а также самих кредиторов по отношению друг к другу. Думается, именно конструкция принципов добросовестности и справедливости следует из слов профессора Г.Ф. Шершеневича о том, что «цель конкурсного процесса заключается в равномерном удовлетворении всех кредиторов и устранении случайных преимуществ одного перед другими» [37, С. 162]. Профессор В.Ф. Попондопуло в качестве одного из основных принципов называет «обеспечение защиты прав и интересов кредиторов в деле о банкротстве, исходя из начала равенства конкурирующих кредиторов» $[24$, C. 44].

Будучи заинтересованными в получении удовлетворения в наибольшем объеме, кредиторы готовы к злоупотреблению своим правом. В рамках процедуры банкротства кредиторы едва ли имеют своей прямой целью причинить вред другим участникам правоотношений (хотя случается и такое); вред скорее является последствием того, что недобросовестный кредитор ставит свои интересы выше остальных, вовсе не учитывая их. В связи с этим суды должны определять законность требований и их объемов исходя из указанных принципов, применяя при этом их в совокупности.

Профессор М.В. Телюкина считает пропорциональность и соразмерность при удовлетворении требований кредиторов в порядке очередности одним из важнейших принципов конкурсного права [31, С. 12]. Исследуя правовые средства достижения целей конкурсного права, О.В. Пустошкин отмечал, что «институт банкротства в России строится на следующих принципах: обоснованность возбуждения дела о несостоятельности должника и введения конкретной процедуры банкротства; управляемость конкурсных отношений; соблюдение баланса интересов должника и кредиторов в процессе реализации конкретных правовых средств» [29, С. 9-10].

Представляется, что в качестве основного правового средства реализации названных выше принципов конкурсного права выступает реестр требований кредиторов. В Российской Федерации порядок включения в реестр требований кредиторов установлен Федеральным законом от 26.10.2002 N127-Ф3 «О несостоятельности (банкротстве)» [34]. В соответствии с нормами указанного закона реестр требований кредиторов ведет арбитражный управляющий или реестродержатель (привлечение последнего обязательно, если кредиторов более пятисот). Требования кредиторов включаются в реестр требований кредиторов и исключаются из него исключительно на основании вступивших в силу судебных актов. 
Реестр требований кредиторов формируется с целью подготовки и проведения собрания кредиторов, в котором имеют право участвовать только реестровые кредиторы. Внесению в реестр подлежат лишь те требования, которые надлежащим образом установлены. Следует признать, что при формировании реестра требований кредиторов, то есть в условиях конкуренции прав кредиторов, неизбежно возникает проблема злоупотребления правом и недобросовестного поведения участников.

Согласно правовой позиции Конституционного Суда Российской Федерации, изложенной в Постановлениях от 22.07.2002 № 14-П [27] и от 19.12.2005 N12-П [28], процедуры банкротства носят публично-правовой характер; разрешаемые в ходе процедур банкротства вопросы влекут правовые последствия для широкого круга лиц (должника, текущих и реестровых кредиторов, работников должника, его учредителей и т.д.). С учетом специфики дел о банкротстве при установлении требований кредиторов в деле о банкротстве установленными могут быть признаны только требования, в отношении которых представлены достаточные доказательства наличия и размера задолженности. Целью проверки судом обоснованности требований является недопущение включения в реестр недолжных требований, поскольку такое включение приводит к нарушению прав и законных интересов кредиторов, имеющих обоснованные требования, а также должника и его учредителей (участников).

При установлении требований в деле о банкротстве не подлежит применению часть 3.1 статьи 70 Арбитражного процессуального кодекса РФ [3], согласно которой обстоятельства, на которые ссылается сторона в обоснование своих требований, считаются признанными другой стороной, если они ею прямо не оспорены или несогласие с такими обстоятельствами не вытекает из иных доказательств, обосновывающих представленные возражения относительно существа заявленных требований; также при установлении требований в деле о банкротстве признание должником или арбитражным управляющим обстоятельств, на которых кредитор основывает свои требования (ч. 3 ст. 70 АПК РФ), само по себе не освобождает другую сторону от необходимости доказывания таких обстоятельств.

Следовательно, в деле о банкротстве именно суд обязан вне зависимости от доводов лиц, участвующих в деле, оценить действительность заявленного требования о включении в реестр и соответствие закону процессуальных и материально-правовых интересов заявителя.

Именно критерий «соответствие закону» включает в себя проверку судом добросовестного поведения и отсутствия злоупотребления правом кредитором в конкурсных отношениях. Большим недостатком в соответствующем правовом регулировании является отсутствие общих установленных критериев для определения добросовестности действий кредиторов. Неурегулированность этого аспекта процедуры банкротства является следствием многообразия возможных действий со стороны кредиторов, и нарушает принцип правовой определенности, отдает такие критерии на усмотрении судов, тем самым ставит участников правоотношений в беззащитное положение, поскольку они не могут знать, какое именно поведение может быть расценено как недобросовестное.

Справедливости ради следует отметить, что действующий Ф3 «О несостоятельности (банкротстве)» содержит механизмы, препятствующие возможному злоупотреблению процессуальными правами. Так, в соответствии с п. 10 ст. 16 этого Закона разногласия по требованиям кредиторов или уполномоченных органов, подтвержденным вступившим в законную силу решением суда в части их состава и размера, не подлежат рассмотрению арбитражным судом, а заявления о таких разногласиях подлежат возвращению без рассмотрения, за исключением разногласий, связанных с исполнением судебных актов или их пересмотром. Пункт 4 ст. 60 Закона о банкротстве устанавливает, что заявления и жалобы, поданные лицами, не имеющими права на обжалование, либо с нарушением установленного данной статьей порядка, подлежат возвращению.

Как разъяснял Верховный Суд Российской Федерации, совершая мнимые либо притворные сделки их стороны, будучи заинтересованными в сокрытии от третьих лиц истинных мотивов своего поведения, как правило, верно оформляют все деловые бумаги, но не стремятся создавать реальные правовые последствия, соответствующие тем, что указаны в составленных ими докумен$\operatorname{Tax}[22]$.

В судебной практике все более четко прослеживается тенденция к увеличению количества отказов судами во включении в реестр требований кредиторов именно на основании несоблюдения кредитором принципа добросовестности. Видится верным, что такой подход судов к проблеме формирует в деловой среде более привлекательный образ истинно добросовестного поведения, а не отражение его в документах лишь для вида.

Так, к примеру, 10-й арбитражный апелляционный суд по делу № A41-98974/18 отменил решение суда первой инстанции о включении в реестр требований кредиторов. В обоснование выводов судом в частности указано, что «стандарты доказывания в деле о банкротстве являются более строгими, чем в условиях неосложненного процедурой банкротства состязательного процесса, при 
этом арбитражный суд вправе и должен устанавливать реальность положенных в основу хозяйственных отношений, предлагая всем заинтересованным лицам предоставить достаточные и взаимно не противоречивые доказательства». По данному делу судом был сделан вывод о недобросовестности поведения исходя из аффилированности кредитора к должнику. Судом применена позиция Постановления Пленума Высшего Арбитражного Суда Российской Федерации № 63 от 23.12.2010 «О некоторых вопросах, связанных с применением главы III.1 Федерального Закона «О несостоятельности (банкротстве)» [26], в котором указано, что «наличие в действиях сторон злоупотребления правом, в том числе выраженного в предъявлении подконтрольного требования и для целей нарушения прав конкурсных кредиторов, уже само по себе достаточно для отказа во включении требований заявителя в реестр». Названное Постановление Пленума ВАС направлено на противодействие включению в реестр требований кредиторов должника требований, основанных на сделках, имеющих явные пороки, свидетельствующие о недобросовестности должника и кредитора при заключении сделки и последующем предъявлении требования кредитором.

Описанный подход суда видится автору настоящей статьи недостаточно логичным, в силу отсутствия в ГК РФ прямого указания на необходимость более жестких подходов к доказыванию в делах о банкротстве, в том числе при установлении наличия либо отсутствия признаков недобросовестности, злоупотребления правом.

На наш взгляд, необходима выработка критериев добросовестности в конкурсных отношениях. Хотя в настоящее время принцип добросовестности при формировании реестра требования кредиторов и понимается как общий принцип гражданского права исходя из содержания, которым он наделяется Гражданским кодексом РФ и Постановлением Пленума Верховного Суда РФ № 25, такой подход является слишком обширным для применения в конкретных конкурсных правоотношениях, вследствие чего требуется выработка собственных критериев на основе анализа судебной практики.

При формировании гражданско-правового регулирования важно сохранять общую стабильность, предсказуемость практики судов, повышать научную обоснованность вынесенных решений, ведь именно такой подход будет соответствовать общеправовому принципу правовое определенности, а также позволит формировать позитивное отношение участников гражданских правоотношений к правопорядку и судебной системе.

При этом, на наш взгляд, очевидна необходимость формирования и ведения реестра требований кредиторов сквозь призму применения принципов разумности, добросовестности и справедливости.

7. Алексеев С. С. Общая теория права: Курс в 2 томах. Т. 1. М., 1981.

8. Аракелян А. Ю. Справедливость в российском гражданском праве: Дис. ... канд. юрид. наук. Краснодар, 2008.

9. Арбитражный процессуальный кодекс Российской Федерации от 24.07.2002 N95-Ф3 (ред. 0т 13.12.2019). Собрание законодательства РФ», 29.07.2002, N30, Ст. 3012.

10. Антонов В. Ф. Содержательная характеристика злоупотребления правом // Законы России: опыт, анализ, практика. 2018. N1.

11. Белов В. А. Добросовестность, разумность и справедливость как принципы гражданского права // Законодательство. 1998. N8.

12. Белоликов А. И. Принципы банкротства // Право и экономика. 2004. N8.

13. Богданов Д. Е. Справедливость как основное начало гражданско-правовой ответственности в российском и зарубежном праве: Монография. М.: Проспект, 2013.

14. Вайпан В. А. Реализация принципа социальной справедливости а правовом регулировании предпринимательской деятельности. дисс.докт.юрид. наук. 12.00.03. M. 2019.

15. Вайпан В. А. Принцип справедливости в гражданском праве и судебное усмотрение // Гражданское право. 2018. N1.

16. Виниченко Ю. В. Разумность и справедливость как принципы гражданского права и начала функционирования системы гражданского оборота // Вестник Пермского университета. Юридические науки. 2014. N3.

17. Герлах А. Справедливость как принцип социалистического права: Автореф. дис. . . . канд. юрид. наук. М., 1983.

18. Гражданский кодекс Российской Федерации (часть первая) от 30.11.1994 № 51-Ф3 (ред. от 01.01.2020) // Собрание законодательства РФ, 1994. № 32. Ст. 3301

19. Гринберг Л.Г., Новиков А. И. Критика современных буржуазных концепций справедливости. Л. 1977.

20. Грудицына Л. Ю. Концептуальные основы формирования институтов гражданского общества в Российской Федерации // Российская юстиция. 2008. № 12.

21. Егоров А. В. Принцип добросовестности в Гражданском кодексе РФ: первые шаги реформы // Legal insight. 2013 . № 2.

22. Иванова С. А. Принцип справедливости в гражданском праве России: дис. ... д-ра юрид. наук: 12.00.01, 12.00.03. М., 2006.

23. Карелина С. А. Принципы правового регулирования отношений, возникающих в связи с несостоятельностью (банкротством) должника // Предпринимательское право. 2008. N2. 
24. Коновалов А. В. Принцип добросовестности в новой редакции Гражданского кодекса Российской Федерации и в судебной практике // Право. Журнал Высшей школы экономики. 2016. № 4.

25. Маликов А. Ф. Вопрос соотношения принципа равенства кредиторов (pari passu) с пресекательным сроком на включение в реестр кредиторов // Вестник экономического правосудия Российской Федерации. 2019. N1.

26. Нам К. В. Принцип добросовестности. Система и бессистемность // Вестник гражданского права. 2019. Т. 19. № 1.

27. Нам К. В. Развитие принципа добросовестности (treu und glauben) современный этап. Внутренняя систематика // Вестник экономического правосудия Российской Федерации. 2018. № 7.

28. Определения Верховного Суда Российской Федерации от 11.07.2017 по делу N A40-201077/2015, от 06.07.2017 года по делу N A32-19056/2014.

29. Пахаруков А. А. Реализация принципа соразмерности в правовом регулировании отношений несостоятельности // Предпринимательское право. Приложение «Право и Бизнес». 2018. N3.

30. Попондопуло В. Ф. Некоторые проблемы совершенствования законодательства о банкротстве // Журнал предпринимательского и корпоративного права. 2016. N1. C. 44.

31. Постановление Пленума Верховного Суда РФ от 23.06 .2015 N25 «0 применении судами некоторых положений раздела І части первой Гражданского кодекса Российской Федерации». Бюллетень Верховного Суда РФ», N8, август, 2015

32. Постановление Пленума ВАС РФ от 23.12.2010 N63 (ред. от 30.07.2013) «0 некоторых вопросах, связанных с применением главы III.1 Федерального закона «0 несостоятельности (банкротстве)» Вестник ВАС РФ», N3, март, 2011.

33. Постановление Конституционного Суда РФ от 22.07.2002 N14-П «По делу о проверке конституционности ряда положений Федерального закона «0 реструктуризации кредитных организаций», пунктов 5 и 6 статьи 120 Федерального закона «0 несостоятельности (банкротстве)» в связи с жалобами граждан, жалобой региональной общественной организации «Ассоциация защиты прав акционеров и вкладчиков» и жалобой ОАО «Воронежское конструкторское бюро антенно-фидерных устройств» «Вестник Конституционного Суда РФ», N6, 2002, «Вестник Конституционного Суда РФ», N1, 2003 (Особое мнение).

34. Постановление Конституционного Суда РФ от 19.12.2005 N12-П «По делу о проверке конституционности абзаца восьмого пункта 1 статьи 20 Федерального закона «0 несостоятельности (банкротстве)» В связи с жалобой гражданина А. Г. Меженцева» «Вестник Конституционного Суда РФ», N1, 2006.

35. Пустошкин 0. В. Правовые средства достижения цели института несостоятельности (банкротства) юридического лица: Дис. ... канд. юрид. наук. Самара, 2005.

36. Сердитова Е. Н. Некоторые аспекты применения норм о доказывании при рассмотрении в деле о банкротстве обособленных споров о включении требования в реестр требований кредиторов должника // Вестник гражданского процесса. 2019. N1.

37. Телюкина М. В. Конкурсное право. Гражданско-правовые проблемы: Дис. ... д-ра юрид. наук. М., 2003.

38. Телюкина М. В. Основы конкурсного права. M.: Walters Kluwer, 2004.

39. Телюкина М. В. Статус текущих кредиторов в конкурсном процессе // Юридический мир. 2002. N11.

40. Федеральный закон от 26.10.2002 N127-Ф3 (ред. от 24.04.2020) «0 несостоятельности (банкротстве)» // Собрание законодательства РФ, 2002. № 43. Ст. 4190.

41. Федотов Д.В. К вопросу о способах противодействия включению в реестр требований кредиторов фиктивной задолженности, подтвержденной решением суда // Российский судья. 2019. N2.

42. Шамшурин Л. Л. Справедливость как принцип российского цивилистического процессуального права // Арбитражный и гражданский процесс. 2016. N11.

43. Шершеневич Г. Ф. Курс торгового права. Т. IV: Торговый процесс. Конкурсный процесс. М.: Статут, 2003.

44. Яковлев В. Ф. Россия: экономика, гражданское право (вопросы теории и практики). М., 2000.

45. Finch V. Corporate insolvency law: perspectives and principles. Cambridge, 2002. Goode R. Principles of Corporate Insolvency Law. 4th ed. London, 2011.

46. McBryde W.W., Flessner A., Kortmann S. C.J.J. Principles of European Insolvency Law // Series Law of Business and Finance. Vol. 4. Deventer, 2003.

() Данилюк Лариса Александровна ( Moscow.advocate@mail.ru).

Журнал «Современная наука: актуальные проблемы теории и практики» 